\title{
FEATURES OF BREAK-EVEN POINT DETERMINATION IN MULTI-PRODUCT
} PRODUCTION

Аннотация. Исследовань возможности использования информации, формируемой при расчете точки безубыточности в многопродуктовом производстве, для принятия решений о доходности каждого вида продукиии и решений по управлению структурой продуктового портфеля.

Ключевые слова: точка безубыточности, многопродуктовое производство, доходность продукции, структура продуктового портфеля.

Abstract. The possibilities of using the information generated when calculating the break-even point in multi-product production for making decisions about the profitability of each type of product and decisions on managing the structure of the product portfolio are investigated.

Keywords: break-even point, multi-product production, product profitability, product portfolio structure.

Проблема, на решение которой направлено данное исследование, - это недостаточно полное исследование возможностей использования информации, полученной в ходе определения точки безубыточности в многопродуктовых производствах для определения доходности каждого вида продукции и обоснования структуры продуктового портфеля, что объясняет актуальность исследования.

Проблема распределения расходов на управление, относящихся по большей части к постоянным, имеет вековую историю и ее актуальность возрастает, что объясняется:

- расширением ассортимента продукции предприятий;

- развитием автоматизированных производств, ведущим к увеличению доли расходов на управление (общехозяйственных расходов);

- снижением удельного веса заработной платы производственных рабочих в совокупных расходах [1].

Цель исследования - выявление резервов повышения уровня достоверности информации, используемой при определении точки безубыточности в многопродуктовом производстве и использования этой информации при принятии управленческих решений.

Задачи исследования:
- систематизация существующих подходов к расчету точки безубыточности в многопродуктовых производствах;

- формирование критериев выбора подходов к расчету точки безубыточности;

- разработка и апробация моделей, позволяющих рассчитать точку безубыточности в многопродуктовых производствах.

Объектами исследования являются хозяйствующие субъекты, выпускающие широкий ассортимент продукции и имеющие значительный удельный вес общехозяйственных расходов (косвенных и в большей степени постоянных) в совокупных расходах.

Предмет исследования - методы определения точки безубыточности в многопродуктовых производствах и оценка их влияния на принятие управленческих решений.

Точка безубыточности - это количество продукции, суммарный маржинальный доход от реализации которой покрывает условно-постоянные расходы [2].

При определении точки безубыточности расходы классифицируются на постоянные и переменные. Они определяются в зависимости от того, меняются ли они в ответ на колебания одного фактора (независимой переменной). В качестве независимой переменной наиболее часто выбирается объем производства (количество и стоимость) [2]. 
По сути, большая часть управленческих (общехозяйственных) расходов может быть отнесена к постоянным.

При этом недостаточно исследованы возможности использования информации, получаемой в ходе определения точки безубыточности для принятия решений по определению доходности каждого вида продукции и при формировании продуктового портфеля.

Рассмотрим особенности расчета точки безубыточности в моногопродуктовом производстве.

Условно для формирования модели расчета принимаем, что организация продает

Таблица 1 - Определение точки безубыточности многопродуктового производства в целом по организации

\begin{tabular}{|l|l|c|c|c|c|}
\hline \multirow{2}{*}{ № } & \multicolumn{1}{|c|}{ Показатель } & Продукт G & Продукт R & Продукт Q & Всего \\
\cline { 3 - 6 } & & A & Б & В & Г \\
\hline 1 & Выручка от реализации, руб. & 30000 & 60000 & 10000 & 100000 \\
\hline 2 & Переменные затраты, руб. & 24000 & 40000 & 5000 & 69000 \\
\hline 3 & Маржинальная прибыль, руб. & 6000 & 20000 & 5000 & 31000 \\
\hline 4 & $\begin{array}{l}\text { Доля маржинальной прибыли в выручке (строка 3 столбец Г / строка } 1 \\
\text { столбец Г × 100\%), \% }\end{array}$ & 31,00 \\
\hline 5 & Постоянные затраты, руб. & 18600 \\
\hline 6 & Прибыль (стр. 3 столбец Г - стр. 5 столбец Г), руб. & 12400 \\
\hline 7 & $\begin{array}{l}\text { Точка безубыточности в целом по организации, руб. (строка 5 столбец Г / } \\
\text { строка 4 столбец Г × 100), руб. }\end{array}$ & 60000 \\
\hline
\end{tabular}

Использование первой модели не обеспечивает возможность определения доходности каждого вида продукции - рентабельности продаж и определения структуры продуктового портфеля по рентабельности продаж.

Таблица 2 - Определение точки безубыточности многопродуктового производства по каждому виду продукции с использованием базы распределения постоянных расходов «Маржинальная прибыль»

\begin{tabular}{|c|l|c|c|c|c|}
\hline \multirow{2}{*}{$№$} & \multicolumn{1}{|c|}{ Показатель } & Продукт G & Продукт R & Продукт Q & Всего \\
\cline { 3 - 6 } & \multicolumn{1}{|c|}{ А } & Б & В & $\Gamma$ \\
\hline 1 & Выручка от реализации, руб. & 30000 & 60000 & 10000 & 100000 \\
\hline 2 & $\begin{array}{l}\text { Доля каждого продукта в выруч- } \\
\text { ке от продаж, долей единицы }\end{array}$ & 0,30 & 0,60 & 0,10 & 1,00 \\
\hline 3 & Переменные затраты, руб. & 24000 & 40000 & 5000 & 69000 \\
\hline 3.1 & $\begin{array}{l}\text { Удельный вес переменных за- } \\
\text { трат в выручке, долей единицы }\end{array}$ & 0,80 & 0,67 & 0,50 & 0,69 \\
\hline 4 & Маржинальная прибыль, руб. & 6000 & 20000 & 5000 & 31000 \\
\hline
\end{tabular}

три вида продукции. Проведем расчеты с использованием существующих на данный момент методик расчета точек безубыточности в многопродуктовом производстве и представим их сравнительный анализ.

Первый вариант определения точки безубыточности многопродуктового производства не предполагает распределения постоянных затрат по видам продукции, а точка безубыточности определяется в целом по предприятию. Модель расчета точки безубыточности многопродуктового производства в первом варианте представлена в таблице 1 . Условно назовем ее первой моделью.
Решение этой проблемы предлагается в модели (таблица 2), использующей в качестве базы распределения постоянных затрат «Маржинальной прибыли». 


\begin{tabular}{|c|c|c|c|c|c|}
\hline 5 & $\begin{array}{l}\text { Доля маржинальной прибыли в } \\
\text { выручке (строка } 4 \text { / строка } 1 \text { × } \\
100 \%), \%\end{array}$ & 20,00 & 33,33 & 50,00 & 31,00 \\
\hline 6 & \multicolumn{4}{|l|}{ Постоянные затраты, руб. } & 18600 \\
\hline 7 & \multicolumn{5}{|c|}{ Распределение постоянных затрат на каждый вид продукции } \\
\hline 7.1 & \multicolumn{5}{|c|}{ База распределения постоянных затрат - маржинальная прибыль } \\
\hline 7.2 & \multicolumn{4}{|c|}{$\begin{array}{l}\text { Коэффициент распределения постоянных затрат (стр. } 6 \text { столбец Г / стр. } 4 \\
\text { столбец Г), долей единицы }\end{array}$} & 0,60 \\
\hline 7.3 & $\begin{array}{l}\text { Суммы постоянных затрат на } \\
\text { каждый вид продукции, руб. }\end{array}$ & 3600 & 12000 & 3000 & 18600 \\
\hline 8 & Прибыль, руб. & 2400 & 8000 & 2000 & 12400 \\
\hline 9 & $\begin{array}{l}\text { Точка безубыточности (стр. } 7.3 / \\
\text { стр. } 5 \times 100), \text { руб. }\end{array}$ & 18000 & 36000 & 6000 & 60000 \\
\hline 10 & Рентабельность продаж, \% & 8,00 & 13,33 & 20,00 & 12,40 \\
\hline 11 & $\begin{array}{l}\text { Структура продуктового порт- } \\
\text { феля по рентабельности продаж } \\
\text { (расчет по методу средневзве- } \\
\text { шенной), \% }\end{array}$ & \multicolumn{3}{|c|}{$0,30 \times 8,00+0,6 \times 13,33+0,1 \times 20,00$} & 12,40 \\
\hline
\end{tabular}

Подход, представленный во второй модели, позволяет определить точку безубыточности, не только в целом по предприятию, но и по каждому виду продукции.

Выбор в качестве базы распределения постоянных затрат «Маржинальной прибыли» обоснован по двум критериям: измеримости величины и экономической обоснованности, поскольку базируется на принципе распределения косвенных расходов с учетом доходности. Вторая модель дает инструменты для управления бизнесом, уровень обоснования принимаемых решений значительно выше, чем в первой модели. Таким образом, сравнение базовых показателей, формируемых в первой и второй моделях распределения постоянных затрат с точки зрения возможности их использования для принятия управленческих решений по точке безубыточности, дает однозначный вывод о преимуществе второй модели.

Кроме того, вторая модель, базирующаяся на маржинальном анализе, в нашем исследовании дополнена и адаптирована для целей определения доходности каждого вида продукции и для управления структурой продуктового портфеля. Это расширяет возможности использования данного инструмента управления бизнесом.
Разработанные в ходе исследования модели универсальны и могут использоваться субъектами хозяйствования в любых видах деятельности при широком ассортименте выпускаемой продукции, выполняемых работ и оказываемых услуг, при любых масштабах деятельности и организационноправовых формах. Вторая модель может использоваться для обоснования принимаемых управленческих решений не только в части определения точки безубыточности, но и при определении доходности каждого вида продукции и при обосновании структуры продуктового портфеля.

Модели выполнены с использованием Excel, содержат алгоритмы расчета, понятны и просты, позволяют моделировать ситуацию и дать ответ на вопрос: «что будет, если?».

Методика маржинального анализа предполагает определение точки безубыточности и запаса финансовой прочности. Практическая ценность предлагаемого инструмента в том, что он дополнен и адаптирован для целей определения доходности каждого вида продукции и для управления структурой продуктового портфеля, что позволяет расширить круг решаемых задач и в определенной мере экономить рабочее время аналитика. 


\section{СПИСОК ЛИТЕРАТУРЫ}

1. Костюкова Е.И. Бухгалтерский управленческий учет: Учебное пособие / Е.И. Костюкова [и др.]; под ред. Е.И. Костюковой. М.: КНОРУC, 2015. 270 c.
2. Григорьева Т.И. Финансовый анализ для менеджеров: оценка, прогноз / Т.И. Григорьева. М.: Юрайт, 2013. 462 с.

УДК 658.1

Бычкова Гульфира Мубараковна, к.э.н., доцент, доцент кафедры «Экономика, маркетинг и психология управления», ФГБОУ ВО «Ангарский государственный технический университет», тел.: 89021721748

УПРАВЛЕНИЕ АМОРТИЗАЦИОННЫМИ ОТЧИСЛЕНИЯМИ

Bychkova G.M.

\section{MANAGEMENT OF DEPRECIATION}

Аннотация. Систематизированы основные факторы, влияющие на выбор способа и норм начисления амортизации. Разработана матрица, сопоставляющая изели бизнеса и факторы, влияющие на величину амортизации, и характер изменения финансовых показателей организачии.

Ключевые слова: способ начисления амортизации, факторы, иели бизнеса, финансовые показатели, изменение.

Abstract. The main factors influencing the choice of the method and norms of depreciation are systematized. A matrix is developed that compares the business goals and factors affecting the amount of depreciation and the nature of changes in the financial performance of the organization.

Keywords: method of depreciation, factors, business objectives, financial performance, change.

Амортизационная политика является составной частью финансовой политики. Управление амортизационными отчислениями является тактической задачей и включает в себя выбор способа начисления амортизации, обоснование норм амортизации, использование накопленных амортизационных отчислений на финансирование развития производства. Основным, но не единственным результатом управления, является смещение налоговых выплат на более поздние периоды.

Проблема, на решение которой направлено данное исследование, - это недостаточно полное исследование факторов, влияющих на формирование амортизационной политики и ее результаты.

Цель исследования - выявление и систематизация факторов, влияющих на выбор способа и нормы начисления амортизации, и оценка их влияния на финансовые показатели деятельности хозяйствующего субъекта.

Задачи исследования:

- систематизация существующих способов начисления амортизации в бухгалтер- ском учете и оценка их влияния на показатели финансовой деятельности;

- систематизация факторов, влияющих на выбор способов и норм начисления амортизации;

- разработка и апробация моделей, позволяющих расчетным путем обосновать выбор способа и норм амортизации.

Объектами исследования являются хозяйствующие субъекты, имеющие в собственности объекты основных средств (ОС).

Предмет исследования - способы и нормы начисления амортизации объектов основных средств.

Основные средства - это часть основного авансированного капитала, вложенного во внеоборотные активы [1]. Они участвуют во многих производственных циклах и возмещают свою стоимость из выручки по частям, по мере износа при помощи амортизации.

Амортизация - это процесс переноса стоимости основного капитала на готовую продукцию. Основное предназначение амортизационных отчислений - это возмещение стоимости ОС, накопление средств на их обновление. 